\title{
Experimentally induced hyperchloremic and DL-lactic acidosis in calves: An attempt to study the effects of oral rehydration on acid-base status
}

\author{
L. Schwedhelm,* D. Kirchner,* B. Klaus, † and L. Bachmann*1 \\ *Institute for Animal Nutrition, Nutrition Diseases and Dietetics, Faculty of Veterinary Medicine, Universität Leipzig, Gustav-Kühn-Str. 8, \\ 04159 Leipzig, Germany \\ †Institute for Medical Informatics, Statistics and Epidemiology (IMISE), Universität Leipzig, Härtelstraße 16-18, 04107 Leipzig, Germany
}

\begin{abstract}
Many diarrheic calves suffer from metabolic acidosis, which is commonly treated by oral rehydration therapy. Oral rehydration solutions can be prepared in water, milk, or milk replacer. Therefore, the aim of the study was to verify dietary effects of water- or milk replacerbased oral rehydration solutions on parameters of acidbase balance in calves with experimentally induced hyperchloremic and DL-lactate acidosis. In 12 calves, hyperchloremic or DL-lactate acidosis was induced by $\mathrm{HCl}$ or DL-lactic acid infusions according to protocols outlined in previous literature. Immediately after induction, the calves were fed with milk replacer or water- or milk replacer-based oral rehydration solutions, or remained fasting, respectively. Blood samples were taken to monitor acid-base status over an experimental period of $4 \mathrm{~h}$. Using the protocols, all calves revealed a manifest hyperchloremic or DL-lactate acidosis. Because of high infusion volumes, plasma volume was expanded and effects of feeding regimens on blood parameters were rare. Unexpected clinical aberrations occurred after repeated induction of DL-lactate acidosis: all calves developed a thrombophlebitis of the jugular vein, whereas $\mathrm{HCl}$ infusion had no effect on endothelium. Induction of acidosis via infusion is not suitable to study dietary effects. A protocol to induce acidosis and dehydration simultaneously is required to duplicate the metabolic conditions of diarrheic calves. In further investigations, attention should be focused on effects of D-lactate or its metabolites on endothelial tissue.
\end{abstract}

Key words: calf, acid-base status, D-lactate, oral rehydration

\section{INTRODUCTION}

Neonatal diarrhea causes the greatest number of deaths in dairy calves worldwide (USDA, 2007; Torsein et al., 2011; Azizzadeh et al., 2012). Acidemia

Received August 23, 2012.

Accepted January 2, 2013.

${ }^{1}$ Corresponding author: bachmann@vetmed.uni-leipzig.de and metabolic acidosis often occur in diarrheic calves (Groutides and Michell, 1990; Hartmann et al., 1997); in calves with diarrhea, metabolic acidosis is accompanied by a decrease in strong ion difference (SID) due to hyper-D-lactatemia, hyper-L-lactatemia, hyponatremia, or hyperchloremia, and an increase in acid total $\left(\mathbf{A}_{\text {tot }}\right)$ due to dehydration (Constable et al., 2005; Bachmann et al., 2009a).

Strong ion difference, $\mathrm{A}_{\text {tot }}$, and partial pressure of $\mathrm{CO}_{2}$ (pCO2) are the 3 independent variables of Stewart's acid-base approach, which directly determines plasma pH (Stewart, 1978). Plasma SID can be approximately calculated by using 3 methods: $\left[\mathrm{SID}_{3}\right]=\left[\mathrm{Na}^{+}\right]+\left[\mathrm{K}^{+}\right]$ $-\left[\mathrm{Cl}^{-}\right] ;\left[\mathrm{SID}_{4}\right]=\left[\mathrm{Na}^{+}\right]+\left[\mathrm{K}^{+}\right]-\left[\mathrm{Cl}^{-}\right]-[$lactate $]$; or $\left[\mathrm{SID}_{6}\right]=\left[\mathrm{Na}^{+}\right]+\left[\mathrm{K}^{+}\right]+\left[\mathrm{Ca}^{2+}\right]+\left[\mathrm{Mg}^{2+}\right]-\left[\mathrm{Cl}^{-}\right]-[\mathrm{lac}-$ tate] (Staempfli and Constable, 2003). Acid total is the term for plasma nonvolatile buffer ion concentration, which has been experimentally determined for calf's plasma: $\left[\mathrm{A}_{\text {tot }}\right]=0.343 \times$ plasma total protein $(\mathrm{g} / \mathrm{L})$ or $\left[\mathrm{A}_{\text {tot }}\right]=0.622 \times$ albumin $(\mathrm{g} / \mathrm{L})$ (Constable et al., 2005).

To study the effects of lactatemia and hyperchloremia, several protocols of experimentally inducing hyper-Dlactate, hyper-L-lactate, and hyperchloremic acidosis in calves have been published (Lorenz et al., 2005; Abeysekara et al., 2007; Gentile et al., 2008). This research has shown that most of the clinical symptoms, such as impaired suckle and palpebral reflex, somnolence, and staggering gait, which were formerly attributed to a decrease in blood $\mathrm{pH}$, were specifically due to hyper-Dlactatemia (Lorenz, 2009).

Oral rehydration therapy is a simple and inexpensive method to treat diarrheal dehydration and acidosis in calves with a sufficient suckle reflex (Constable et al., 2001). Oral rehydration solutions (ORS) with high SID are the most effective treatment for metabolic acidosis by increasing plasma SID (Constable et al., 2005; Bachmann et al., 2009b).

Oral rehydration solutions can be prepared in milk, milk replacer (MR), or water to provide diarrheic calves with electrolytes (Bachmann et al., 2009b; Constable et al., 2009). As it is advisable to continue milk feeding to prevent BW loss in diarrheic calves (Radostits et al., 1975; Garthwaite, et al., 1994), it seems logical 
to feed milk-based ORS to diarrheic calves. However, milk, milk-based, and water-based hypertonic ORS pass the abomasum more slowly than isotonic ORS prepared in water (Bell and Razig, 1973; Sen et al., 2006). Prolonged abomasal passage of ORS may result in delayed correction of acid-base status, which may lead to malfunction of the suckle reflex. Otherwise, the preparation of ORS in milk or MR achieves higher dietary SID values (Bachmann et al., 2009b).

We hypothesized that water- and milk-based ORS provide different effects on acid-base status in cases of metabolic acidosis that might be relevant for efficient oral rehydration management of diarrheic calves. Therefore, the aim of the present study was to determine the effect of feeding MR and ORS prepared in water or MR on experimentally induced hyperchloremic and hyperD/L-lactate acidosis in calves.

\section{MATERIALS AND METHODS}

Experiments were approved by federal authorities for animal research (TVV 15/11, Landesdirektion Leipzig, Germany) and conducted in accordance with the principles and specific guidelines presented in Guidelines for the Care and Use of Agricultural Animals in Research and Teaching (FASS, 2010).

\section{Animals}

Twelve healthy male calves born at a dairy farm near Leipzig, Germany, were used in the study. All calves received $4 \mathrm{~L}$ of colostrum within $2 \mathrm{~h}$ after birth. The calves were transported to the Institute for Animal Nutrition, Nutritional Diseases and Dietetics (Leipzig, Germany) at 2 or $3 \mathrm{~d}$ of life. Calves were kept in calf boxes with straw bedding. Before the start of experiments and between the experimental days, calves were fed 3 times a day (at 0800, 1300, and $1700 \mathrm{~h}, 2 \mathrm{~L}$ per meal) with MR (all-milk-protein, 35\%, Invaso Milk, Invaso GmbH, Ergoldsbach, Germany). Calves had free access to water and were provided with hay and concentrated feed stuff (deukanaS, Deuka, Deutsche
Tiernahrung Cremer GmbH \& Co. KG, Düsseldorf, Germany).

\section{Experimental Design}

Experiments started 3 to $5 \mathrm{~d}$ after birth; between the experimental days the calves had at least $2 \mathrm{~d}$ for recovery. The mean age of calves in all experiments was $10 \pm 5 \mathrm{~d}$. Before the onset of the experiments, calves were fitted with an indwelling catheter in the jugular vein and a blood sample was taken before induction of acidosis. Catheters were secured in place with suture material.

As bacterial and viral challenges do not provide reproducible findings of metabolic acidosis (Walker et al., 1998), induction of acidosis via infusion was chosen. Hyperchloremic acidosis was induced in 6 calves according to Gentile et al. (2008), where $\mathrm{HCl}$ was prepared in physiological $\mathrm{NaCl}$ solution $(400 \mathrm{mmol}$ of $\mathrm{HCl}$ per L, Rotipuran 37\% hydrochloric acid, Roth, Karlsruhe, Germany). Specifications of the infusion solutions used are given in Table 1; the infusion rate was $4.033 \mathrm{~L}$ in 80 min.

DL-Lactate acidosis was triggered in 6 calves following a protocol of Abeysekara et al. (2007). Both D- and L-lactic acid (49.8/50.3\%, Sigma-Aldrich, St. Louis, MO) were formulated as $300 \mathrm{mmol} / \mathrm{L}$ solutions with water for injection (Table 1) and administered via jugular intravenous infusion at an infusion rate of about $20 \mathrm{~mL} / \mathrm{kg}$ per hour. Because D-lactate impairs central nervous function, the infusion volume was adapted to calves' ability to stand and suckle $(2-3.5 \mathrm{~L})$, as these 2 parameters are essential for the realization of a feeding experiment. Directly after induction of hyperchloremic or DL-lactate acidosis, another blood sample was taken.

It was planned that every calf was experimentally acidified at $4 \mathrm{~d}$ to pass the following experimental phases: MR feeding (MR), feeding of water-based ORS (water-ORS), feeding of MR-based ORS (MRORS), and fasting ( 1 experimental period). The calves had at least $2 \mathrm{~d}$ for recovery between the experimental days. In the $\mathrm{HCl}$ group, every calf underwent 4 feeding

Table 1. Osmolality, $\mathrm{pH},\left[\mathrm{Na}^{+}\right],\left[\mathrm{K}^{+}\right],\left[\mathrm{Cl}^{-}\right],\left[\mathrm{SID}_{3}\right]$, and [lactate] in the infusion solutions and feeding regimens

\begin{tabular}{|c|c|c|c|c|c|c|c|}
\hline Item $^{1}$ & $\begin{array}{l}\text { Osmolality } \\
(\mathrm{mOsm} / \mathrm{kg})\end{array}$ & $\mathrm{pH}$ & $\begin{array}{c}{\left[\mathrm{Na}^{+}\right]} \\
(\mathrm{mmol} / \mathrm{L})\end{array}$ & $\begin{array}{c}{\left[\mathrm{K}^{+}\right]} \\
(\mathrm{mmol} / \mathrm{L})\end{array}$ & $\begin{array}{c}{\left[\mathrm{Cl}^{-}\right]} \\
(\mathrm{mmol} / \mathrm{L})\end{array}$ & $\begin{array}{c}{\left[\mathrm{SID}_{3}\right]^{2}} \\
(\mathrm{mmol} / \mathrm{L})\end{array}$ & $\begin{array}{c}\text { [DL-lactate }] \\
(\mathrm{mmol} / \mathrm{L})\end{array}$ \\
\hline $\mathrm{HCl}$ infusion & 459 & 1.20 & 154 & - & 254 & - & - \\
\hline DL-lactate infusion & 279 & 2.32 & - & - & - & - & $\begin{array}{c}270 \\
\text { (D/L:136/134) }\end{array}$ \\
\hline MR & 332 & 5.83 & 30 & 43 & 39 & 34 & - \\
\hline Water-ORS & 361 & 7.65 & 81 & 13 & 45 & 49 & - \\
\hline MR-ORS & 666 & 6.68 & 111 & 56 & 84 & 83 & - \\
\hline
\end{tabular}

${ }^{1} \mathrm{MR}=$ milk replacer; Water-ORS $=$ water-based oral rehydration solution; MR-ORS $=$ MR-based oral rehydration solution.

${ }^{2}\left[\mathrm{SID}_{3}\right]=$ strong ion difference $=\left[\mathrm{Na}^{+}\right]+\left[\mathrm{K}^{+}\right]-\left[\mathrm{Cl}^{-}\right]$. 
experiments as preplanned. Due to adverse reactions after DL-lactic acid infusion (see Results section), it was impossible to perform 4 experimental periods with any 1 calf. Therefore, every feeding regimen was undertaken 4 times instead of 6 , so that every calf participated in 2 or 3 experiments. For the experiments, the calves received $2 \mathrm{~L}$ of MR, water-based ORS, or MR-based ORS after infusion or remained fasting, respectively, and were deprived of water, hay, and concentrates.

Blood samples were taken via jugular catheter before and 15, 30, 45 min and 1, 1.5, 2, 3, and $4 \mathrm{~h}$ after feeding or start of the experimental period. At the end of experimental time, vein catheters were removed and calves were fed $2 \mathrm{~L}$ of ORS or, if necessary, were infused with bicarbonate until $\mathrm{pH}$ returned to reference values. Osmolality, $\mathrm{pH},\left[\mathrm{Na}^{+}\right],\left[\mathrm{K}^{+}\right],\left[\mathrm{Cl}^{-}\right]$, and $\left[\mathrm{SID}_{3}\right]=\left[\mathrm{Na}^{+}\right]$ $+\left[\mathrm{K}^{+}\right]-\left[\mathrm{Cl}^{-}\right]$in the infusion solutions and different feeding regimens were determined or calculated according to the specifications of the manufacturers, respectively (Table 1). Lytafit (Albrecht GmbH, Aulendorf, Germany), the commercial product used in the study, was a $\mathrm{HCO}^{3-}(62 \mathrm{mmol} / \mathrm{L})$ containing ORS. Further ingredients were lactose, glycine, $\mathrm{Ca}^{2+}$, and $\mathrm{Mg}^{2+}$.

\section{Measurements and Analyses}

All samples (lithium heparin vials) were analyzed for total plasma protein (Hitachi 912, Boehringer, Mannheim, Germany; Biuret method; Wokes and Still, 1942), $\left[\mathrm{Na}^{+}\right],\left[\mathrm{K}^{+}\right],\left[\mathrm{Cl}^{-}\right]$(ion selective electrode), albumin (bromocresol green assay), and osmolality (Osmometer K-7400, Knauer, Berlin, Germany; freezing point depression). Blood gas analysis, including $\left[\mathrm{Ca}^{2+}\right]$ (ABL 80 Flex, Radiometer, Copenhagen, Denmark), was performed directly after blood sampling. Then $\left[\mathrm{Ca}^{2+}\right]$ was measured, as there were $\mathrm{pH}$-dependent changes in the concentration of the ionized form, probably because of the $\mathrm{pH}$-dependent protein bound to calcium (GroveWhite and Michell, 2001). Before and after lactic acid infusion, D- and L-lactate in plasma samples, which were prepared in vials containing sodium fluoride, were measured by enzymatic methods using D- and L-lactate dehydrogenase.

Calculated change in plasma volume after feeding was assessed from the plasma protein concentration before infusion $\left(\mathrm{P}_{\mathrm{t}=0}\right)$ and the plasma protein concentration after infusion $\left(\mathrm{P}_{\mathrm{t}=\mathrm{x}}\right)=\left(\mathrm{P}_{\mathrm{t}=0}-\mathrm{P}_{\mathrm{t}=\mathrm{x}}\right) \times 100 / \mathrm{P}_{\mathrm{t}=\mathrm{x}}$ (Van Beaumont et al., 1972).

Based on the concentrations of the electrolytes, albumin, and total protein in plasma the following parameters were calculated: $\left[\mathrm{SID}_{3}\right]=\left[\mathrm{Na}^{+}\right]+\left[\mathrm{K}^{+}\right]-\left[\mathrm{Cl}^{-}\right]$; $\left[\mathrm{SID}_{4}\right]=\left[\mathrm{Na}^{+}\right]+\left[\mathrm{K}^{+}\right]-\left[\mathrm{Cl}^{-}\right]-[$DL-lactate $] ;$acid total $\left[\mathrm{A}_{\text {tot-alb }}\right]=0.622 \times$ [albumin $]$ and $\left[\mathrm{A}_{\text {tot-TP }}\right]=0.343 \times$ [total protein]; strong ion gap (SIG) $\left[\mathrm{SIG}_{\text {alb }}\right]=[$ albu- $\min ] \times\left\{0.622 /\left[1+10^{(7.08-\mathrm{pH})}\right]\right\}-$ anion gap, as well as $\left[\mathrm{SIG}_{\mathrm{TP}}\right]=[$ total protein $] \times\left\{0.343 /\left[1+10^{(7.08-\mathrm{pH})}\right]\right\}$ - anion gap (Constable et al., 2005).

\section{Statistical Analyses}

Data were expressed as mean ( \pm SD) and analyzed by using repeated-measures ANOVA. For the parameters that offered statistically significant effects of time and feeding regimen or statistically significant coherencies between time and feeding regimen, respectively, a Bonferroni test was computed to detect differences within or between the feeding regimens. To test if an influence of the individual calf existed, multivariable linear regression analysis with calf as a dummy variable was also performed between values of [DL-lactate] and $\left[\mathrm{SIG}_{\mathrm{alb}}\right]$ or $\left[\mathrm{SIG}_{\mathrm{TP}}\right]$, respectively. For statistical analysis, the software Statistica (version 7, StatSoft GmbH, Hamburg, Germany) and R (R Core Team, R Foundation for Statistical Computing, Vienna, Austria) was used.

\section{RESULTS}

\section{Effects of $\mathrm{HCl}$ - and DL-Lactic Acid Infusion on Clinical Outcomes}

Hyperchloremic Acidosis. In 8 of the experiments the heart rate of the animals increased considerably, to values of about 160 beats/min (bpm), mostly by an infusion volume of $\geq 3 \mathrm{~L}$. It decreased to normal values between 45 and 60 min after feeding. Two animals developed recurrent muscle contractions of the hind leg and trembling during the infusion. In 2 cases, the suckle reflex became too weak after the infusion, so that these animals refused to drink at all or did not drink the whole amount. One animal showed hemoglobinuria after receiving the drip.

DL-Lactic Acidosis. In cases of calves infused with DL-lactate, severe adverse reactions occurred after repetitive infusion of DL-lactate in several calves. All animals showed a continuing inability to stand with ataxia, impaired coordination, and reduced menace reflex. With increasing infusion volume, the calves preferred to stay in ventral or lateral recumbency. Thus, they retained a well-preserved suckle reflex and could be animated to stand up. Two animals showed increased heart rate and breathing frequency. In 4 cases, animals showed recurrent spasms of the hind leg, muzzle area, and chewing motions. Two animals displayed hemoglobinuria. All animals receiving DL-lactic acid infusion developed a mild to severe thrombophlebitis of the jugular vein following the first infusion rate. After repeated infusion, the effects on the vascular wall increased, such that by 
the end of the experimental phase some of the calves displayed massive and persistent edema around the neck and larynx. Three animals had to be euthanized for animal welfare reasons.

\section{Effects of $\mathrm{HCl}$ - and DL-Lactic Acid Infusion on Acid-Base Status}

Hyperchloremic Acidosis. The infusion with $\mathrm{HCl}$ induced a strong metabolic acidosis with a decrease in $\left[\mathrm{SID}_{3}\right]$ in all calves. Mean $\mathrm{pCO}_{2}$ values decreased directly after the infusion. Still, this reduction was not consistent and it could not be found in all animals. Fifteen minutes after feeding, mean values increased again and kept changing unsteadily during the whole experimental period (Figure 1). Acid total values dropped significantly after the infusion. A significant decrease in $\left[\mathrm{SIG}_{\mathrm{TP}}\right]$ was also observed; $\left[\mathrm{SIG}_{\mathrm{alb}}\right]$ did not change significantly (Table 2).

DL-Lactic Acidosis. Using the protocol, all calves developed marked lactic acidosis with significantly increased [lactate] and significantly decreased $\mathrm{pH}$ values after they received the drip (Table 2). Mean $\mathrm{pCO}_{2}$ values were not affected directly after the infusion, but decreased 15 min after feeding at the latest, and stayed reduced for the remaining experimental period (Figure 2 ). However, this effect was not statistically significant. The $\left[\mathrm{SIG}_{\mathrm{alb} / \mathrm{TP}}\right]$ values decreased significantly, whereas a change in $\left[\mathrm{A}_{\text {tot-alb/TP }}\right]$ was less distinctive and not significant (Table 2).

\section{Effects of $\mathrm{HCl}$ - and DL-Lactic Acid Infusion on Plasma Calcium}

After infusion of $\mathrm{HCl}$ and DL-lactic acid, a significant increase in plasma calcium was observed (Table 2). Plasma calcium concentration increased more in calves infused with $\mathrm{HCl}$ than after DL-lactic acid infusion.

\section{Effects of HCl- and DL-Lactic Acid Infusion on Plasma Osmolality and Volume}

Depending on the osmolality of the infusions, plasma osmolality increased significantly after $\mathrm{HCl}$ infusion (Table 2) and remained unchanged after DL-lactic acid infusion. Plasma volume was elevated due to infusion volume and increased to $+21.06 \pm 5.96 \%$ after $\mathrm{HCl}$ infusion and to $+10.78 \pm 12.55 \%$ after DL-lactic acid infusion.

\section{Dietary Effects on Acid-Base Status}

No influence between the different feeding regimens could be detected in the form of a faster or more pronounced change in $\mathrm{pH}$ in calves with hyperchloremic or lactic acidosis, respectively.

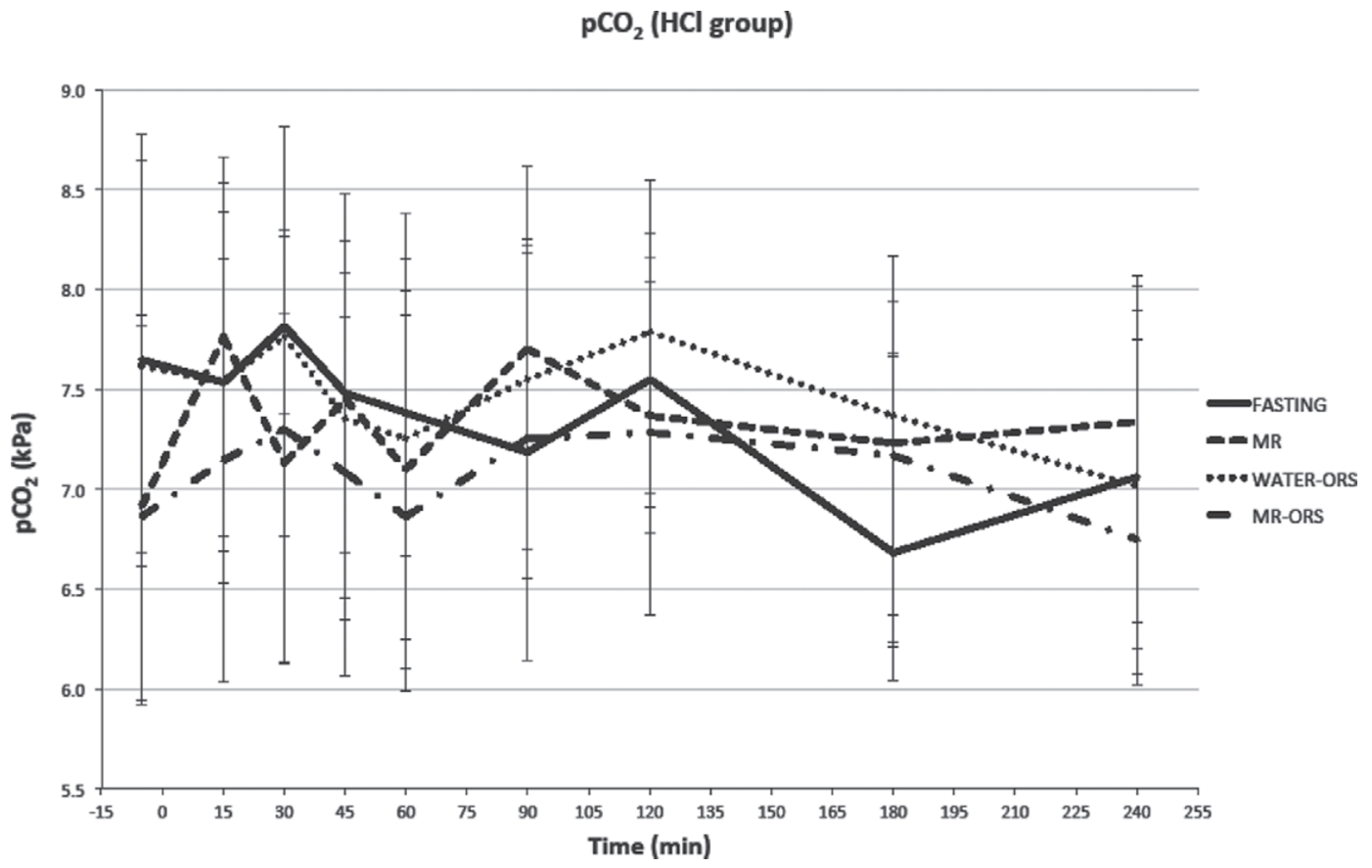

Figure 1. Change in partial pressure of $\mathrm{CO}_{2}\left(\mathrm{pCO}_{2}\right)$ during a 4-h fasting period and after feeding milk replacer (MR) or water- or MR-based oral rehydration solutions (water-ORS or MR-ORS) in calves with experimentally induced hyperchloremic acidosis. 
Table 2. Effects of $\mathrm{HCl}$ and DL-lactic acid infusions on acid-base status ( $\mathrm{pH}$, partial pressure of $\mathrm{CO}_{2}, \mathrm{SID}_{3}, \mathrm{~A}_{\text {tot }}$ ), DL-lactate, plasma calcium, osmolality, and plasma volume (mean $\pm \mathrm{SD})$

\begin{tabular}{|c|c|c|c|c|}
\hline Parameter $^{1}$ & Before & After & Before & After \\
\hline Partial pressure of $\mathrm{CO}_{2}(\mathrm{kPa})$ & $8.18 \pm 0.86$ & $7.26 \pm 1.00$ & $7.44 \pm 0.84$ & $7.61 \pm 1.03$ \\
\hline$\left[\mathrm{SID}_{3}\right](\mathrm{mmol} / \mathrm{L})$ & $46.0 \pm 4.08$ & $25 \pm 3.53^{* *}$ & $45 \pm 3.92$ & $46 \pm 3.62$ \\
\hline$\left[\mathrm{A}_{\text {tot-alb }}\right](\mathrm{mmol} / \mathrm{L})$ & $15.96 \pm 0.97$ & $13.48 \pm 1.18^{* *}$ & $15.83 \pm 1.46$ & $14.80 \pm 0.91$ \\
\hline$\left[\mathrm{A}_{\text {tot-TP }}\right](\mathrm{mmol} / \mathrm{L})$ & $21.30 \pm 2.45$ & $17.49 \pm 2.04^{* *}$ & $20.46 \pm 2.29$ & $18.66 \pm 2.84$ \\
\hline [L-lactate] $(\mathrm{mmol} / \mathrm{L})$ & - & - & $0.48 \pm 0.85$ & $11.48 \pm 0.93^{* *}$ \\
\hline [D-lactate] $(\mathrm{mmol} / \mathrm{L})$ & - & - & $1.05 \pm 0.32$ & $2.21 \pm 0.67^{* *}$ \\
\hline$\left[\mathrm{Ca}^{2+}\right](\mathrm{mmol} / \mathrm{L})$ & $1.28 \pm 0.06$ & $1.72 \pm 0.11^{* *}$ & $1.32 \pm 0.05$ & $1.43 \pm 0.05^{* *}$ \\
\hline Osmolality $(\mathrm{mOsmol} / \mathrm{kg}$ ) & $276.03 \pm 7.77$ & $291.68 \pm 6.89^{*}$ & $276.45 \pm 8.68$ & $271.63 \pm 9.71$ \\
\hline Change in plasma volume (\%) & - & $+21.09 \pm 5.96^{* *}$ & - & $+10.78 \pm 12.55$ \\
\hline
\end{tabular}

${ }^{1}\left[\mathrm{SID}_{3}\right]=$ strong ion difference: $\left[\mathrm{Na}^{+}\right]+\left[\mathrm{K}^{+}\right]-\left[\mathrm{Cl}^{-}\right]$; acid total calculated from albumin $\left[\mathrm{A}_{\text {tot-alb }}\right]=0.622 \times[$ albumin $]$; acid total calculated from total protein $\left[\mathrm{A}_{\text {tot-TP }}\right]=0.343 \times[\mathrm{TP}]$; strong ion gap calculated from albumin $\left[\mathrm{SIG}_{\mathrm{alb}}\right]=[$ albumin $] \times\left\{0.622 /\left[1+10^{(\tau .08-\mathrm{pH})}\right]\right\}-$ anion gap; strong ion gap calculated from total protein $\left[\mathrm{SIG}_{\mathrm{TP}}\right]=$ total protein $] \times\left\{0.343 /\left[1+10^{(7.08-\mathrm{pH})}\right]\right\}-$ anion gap.

${ }^{*} P<0.05,{ }^{* *} P<0.01$ compared with values before infusion.

Hyperchloremic Acidosis. The $\left[\mathrm{SID}_{3}\right]$ values increased faster after feeding in comparison to nonfeeding, but no differences between the feeding regimens were noted. Values of $\left[\mathrm{A}_{\text {tot-TP }}\right]$ increased significantly 45 min after MR-ORS feeding, 90 min after MR feeding or water-ORS feeding, and after $120 \mathrm{~min}$ of the fasting period. An increase of $\left[\mathrm{A}_{\text {tot-alb }}\right] 30 \mathrm{~min}$ after MR feeding was noted and 45 min after water-ORS and MR-ORS feeding. A change in the fasting group appeared after
60 min. The $\left[\mathrm{SIG}_{\mathrm{alb} / \mathrm{TP}}\right]$ values increased significantly 15 min after water-ORS feeding and remained unchanged in all other groups (Table 3).

DL-Lactic Acidosis. The $\left[\mathrm{SID}_{4}\right]$ values showed a faster increase after feeding in comparison to nonfeeding, but no differences were noted between the feeding regimens. Values changed significantly 60 to $90 \mathrm{~min}$ after receiving a diet, whereas no significant change was noted in the fasting group until the end of the

$\mathrm{pCO}_{2}$ (lactate group)

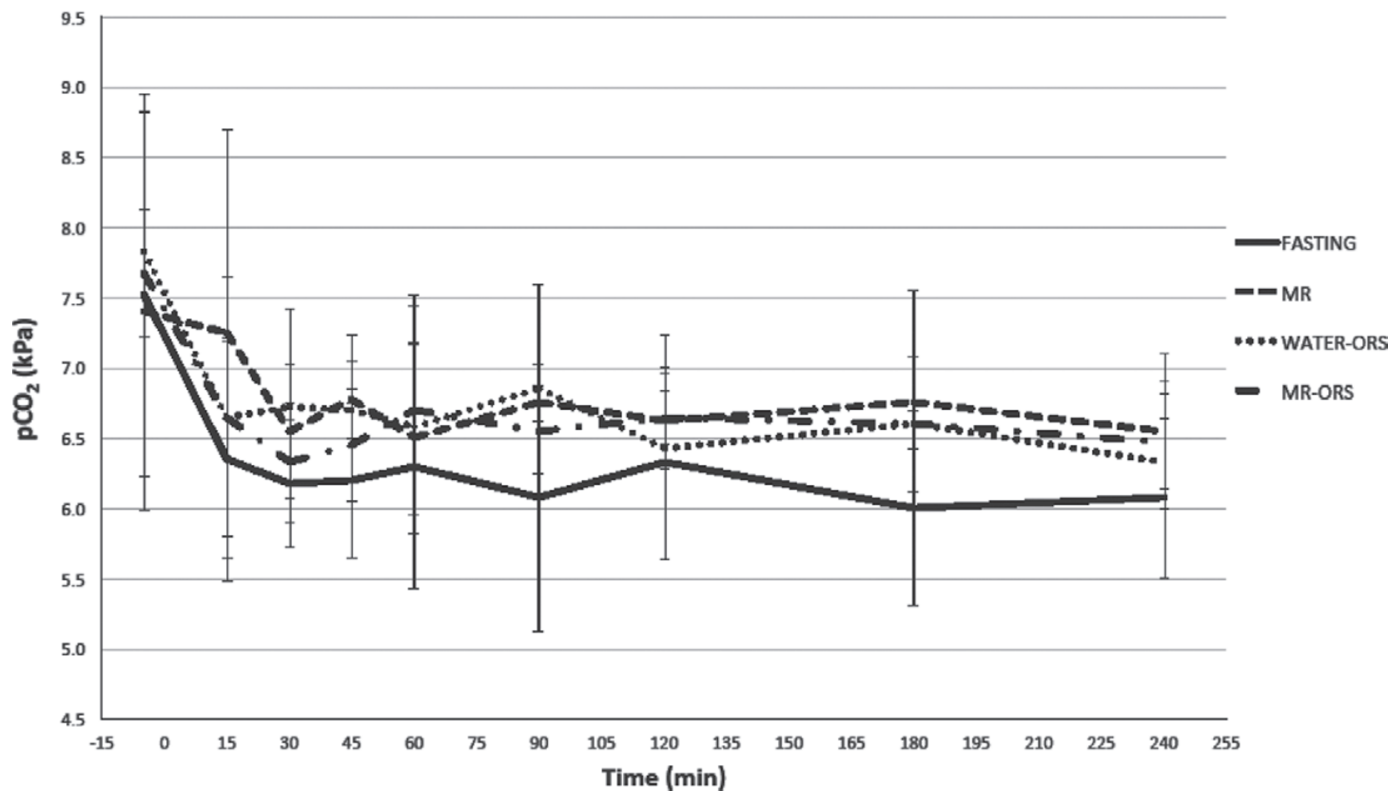

Figure 2. Change in partial pressure of $\mathrm{CO}_{2}\left(\mathrm{pCO}_{2}\right)$ during a 4-h fasting period and after feeding milk replacer (MR) or water- or MR-based oral rehydration solutions (water-ORS or MR-ORS) in calves with experimentally induced DL-lactate acidosis. 
Table 3. Change of plasma parameters (mean \pm SD) during a 4-h fasting period and after feeding milk replacer (MR), water-based oral rehydration solution (Water-ORS), and MR-based ORS (MR-ORS) in calves with experimentally induced hyperchloremic acidosis $(\mathrm{n}=6)$

\begin{tabular}{|c|c|c|c|c|c|c|c|c|c|c|}
\hline Parameter ${ }^{1}$ & Group & $-5 \mathrm{~min}$ & $+15 \min$ & $+30 \mathrm{~min}$ & $+45 \mathrm{~min}$ & $+60 \mathrm{~min}$ & $+90 \mathrm{~min}$ & $+120 \mathrm{~min}$ & $+180 \mathrm{~min}$ & $+240 \min$ \\
\hline \multirow[t]{4}{*}{$\mathrm{pH}$} & Fasting & $7.05 \pm 0.06$ & $7.10 \pm 0.05$ & $7.11 \pm 0.02$ & $7.14 \pm 0.03^{* *}$ & $7.15 \pm 0.02^{* *}$ & $7.18 \pm 0.03^{* *}$ & $7.18 \pm 0.03^{* *}$ & $7.24 \pm 0.03^{* *}$ & $7.24 \pm 0.03^{* *}$ \\
\hline & MR & $7.03 \pm 0.12$ & $7.06 \pm 0.07$ & $7.12 \pm 0.05^{* *}$ & $7.12 \pm 0.04^{* *}$ & $7.15 \pm 0.06^{* *}$ & $7.15 \pm 0.07^{* *}$ & $7.18 \pm 0.07^{* *}$ & $7.22 \pm 0.04^{* *}$ & $7.23 \pm 0.04^{* *}$ \\
\hline & Water-ORS & $7.00 \pm 0.08^{* *}$ & $7.11 \pm 0.05^{* *}$ & $7.13 \pm 0.06^{* *}$ & $7.16 \pm 0.04^{* *}$ & $7.18 \pm 0.04^{* *}$ & $7.20 \pm 0.04^{* *}$ & $7.20 \pm 0.06^{* *}$ & $7.25 \pm 0.05^{* *}$ & $7.28 \pm 0.03^{* *}$ \\
\hline & MR-ORS & $7.01 \pm 0.08$ & $7.08 \pm 0.06$ & $7.10 \pm 0.05$ & $7.12 \pm 0.07^{* *}$ & $7.12 \pm 0.04^{* *}$ & $7.14 \pm 0.05^{* *}$ & $7.16 \pm 0.07^{* *}$ & $7.20 \pm 0.09^{* *}$ & $7.24 \pm 0.06^{* *}$ \\
\hline$\left[\mathrm{Ca}^{2+}\right]$ & Fasting & $1.77 \pm 0.04$ & $1.77 \pm 0.04$ & $1.76 \pm 0.06$ & $1.73 \pm 0.07$ & $1.70 \pm 0.06$ & $1.65 \pm 0.06$ & $1.60 \pm 0.06^{* *}$ & $1.51 \pm 0.04^{* *}$ & $1.49 \pm 0.06^{* *}$ \\
\hline \multirow{3}{*}{$(\mathrm{mmol} / \mathrm{L})$} & MR & $1.74 \pm 0.09$ & $1.77 \pm 0.08$ & $1.68 \pm 0.17$ & $1.64 \pm 0.16$ & $1.62 \pm 0.18$ & $1.58 \pm 0.14^{* *}$ & $1.56 \pm 0.10^{* *}$ & $1.48 \pm 0.08^{* *}$ & $1.47 \pm 0.05^{* *}$ \\
\hline & Water-ORS & $1.66 \pm 0.10$ & $1.70 \pm 0.09$ & $1.67 \pm 0.08$ & $1.63 \pm 0.08$ & $1.63 \pm 0.07$ & $1.60 \pm 0.08$ & $1.56 \pm 0.13$ & $1.51 \pm 0.17^{* *}$ & $1.44 \pm 0.06^{* *}$ \\
\hline & MR-ORS & $1.72 \pm 0.15$ & $1.71 \pm 0.16$ & $1.70 \pm 0.13$ & $1.66 \pm 0.12$ & $1.66 \pm 0.10$ & $1.65 \pm 0.06$ & $1.58 \pm 0.08^{* *}$ & $1.52 \pm 0.06^{* *}$ & $1.48 \pm 0.07^{* *}$ \\
\hline$\left[\mathrm{SID}_{3}\right]$ & Fasting & $28.35 \pm 1.56$ & $30.13 \pm 1.78$ & $31.20 \pm 2.34$ & $31.75 \pm 2.46^{* *}$ & $31.58 \pm 4.21^{*}$ & $33.28 \pm 2.07^{* *}$ & $34.27 \pm 1.95^{* *}$ & $36.10 \pm 2.24^{* *}$ & $36.60 \pm 2.62^{* *}$ \\
\hline \multirow[t]{3}{*}{$(\mathrm{mmol} / \mathrm{L})$} & MR & $24.35 \pm 4.37$ & $27.40 \pm 4.06^{*}$ & $28.70 \pm 4.55^{* *}$ & $28.78 \pm 4.53^{* *}$ & $29.90 \pm 4.17^{* *}$ & $31.05 \pm 3.91^{* *}$ & $32.60 \pm 3.79^{* *}$ & $34.35 \pm 3.54^{* *}$ & $35.42 \pm 3.58^{* *}$ \\
\hline & Water-ORS & $24.52 \pm 3.21$ & $27.28 \pm 1.97$ & $28.95 \pm 2.27^{* *}$ & $30.12 \pm 1.98^{* *}$ & $30.68 \pm 2.11^{* *}$ & $32.12 \pm 2.58^{* *}$ & $34.00 \pm 2.47^{* *}$ & $35.78 \pm 2.20^{* *}$ & $36.45 \pm 2.90^{* *}$ \\
\hline & MR-ORS & $22.97 \pm 2.53$ & $26.57 \pm 2.36^{* *}$ & $27.18 \pm 2.26^{* *}$ & $28.53 \pm 2.43^{* *}$ & $29.22 \pm 2.52^{* *}$ & $30.95 \pm 2.08^{* *}$ & $31.98 \pm 2.70^{* *}$ & $33.50 \pm 3.21^{* *}$ & $35.08 \pm 3.61^{* *}$ \\
\hline \multirow{4}{*}{$\begin{array}{l}{\left[\mathrm{A}_{\text {tot-alb }}\right]} \\
(\mathrm{mmol} / \mathrm{L})\end{array}$} & Fasting & $13.34 \pm 1.10$ & $13.83 \pm 1.12$ & $13.65 \pm 0.91$ & $13.98 \pm 1.21$ & $14.50 \pm 1.28^{*}$ & $14.39 \pm 1.43^{*}$ & $14.71 \pm 1.15^{* *}$ & $15.24 \pm 1.23^{* *}$ & $15.34 \pm 1.31^{* *}$ \\
\hline & MR & $13.73 \pm 1.54$ & $14.43 \pm 1.26$ & $14.88 \pm 1.44^{*}$ & $14.80 \pm 1.49^{*}$ & $15.32 \pm 1.32^{* *}$ & $15.47 \pm 1.43^{* *}$ & $15.84 \pm 1.12^{* *}$ & $15.58 \pm 1.05^{* *}$ & $15.70 \pm 0.89^{* *}$ \\
\hline & Water-ORS & $13.42 \pm 1.34$ & $14.32 \pm 0.97$ & $14.34 \pm 1.17$ & $14.69 \pm 0.95^{* *}$ & $14.44 \pm 0.60$ & $14.87 \pm 0.69^{* *}$ & $15.22 \pm 0.61^{* *}$ & $15.35 \pm 1.24^{* *}$ & $15.24 \pm 0.90^{* *}$ \\
\hline & MR-ORS & $13.41 \pm 0.96$ & $14.35 \pm 1.22$ & $14.46 \pm 1.30$ & $14.90 \pm 1.25^{* *}$ & $15.20 \pm 1.11^{* *}$ & $15.75 \pm 0.81^{* *}$ & $16.00 \pm 1.06^{* *}$ & $15.82 \pm 1.09^{* *}$ & $15.60 \pm 0.96^{* *}$ \\
\hline & Fasting & $19.24 \pm 1.72$ & $19.88 \pm 1.44$ & $19.65 \pm 1.18$ & $20.12 \pm 1.28$ & $20.13 \pm 1.41$ & $20.71 \pm 1.35$ & $21.07 \pm 1.34^{* *}$ & $21.93 \pm 1.35^{* *}$ & $22.13 \pm 1.29^{* *}$ \\
\hline \multirow{3}{*}{$(\mathrm{mmol} / \mathrm{L})$} & MR & $17.48 \pm 2.51$ & $18.09 \pm 2.24$ & $18.54 \pm 2.38$ & $18.56 \pm 2.24$ & $19.03 \pm 1.68$ & $19.42 \pm 1.66^{* *}$ & $20.10 \pm 2.14^{* *}$ & $20.09 \pm 2.12^{* *}$ & $20.63 \pm 2.26^{* *}$ \\
\hline & Water-ORS & $16.69 \pm 1.73$ & $17.65 \pm 1.65$ & $17.78 \pm 2.28$ & $18.14 \pm 1.86$ & $18.01 \pm 1.56$ & $18.53 \pm 1.75^{* *}$ & $18.97 \pm 1.63^{* *}$ & $19.29 \pm 2.00^{* *}$ & $19.37 \pm 1.73^{* *}$ \\
\hline & MR-ORS & $16.56 \pm 1.16$ & $17.71 \pm 1.96$ & $17.84 \pm 2.07$ & $18.41 \pm 1.89^{* *}$ & $19.00 \pm 1.75^{* *}$ & $19.64 \pm 1.40^{* *}$ & $19.93 \pm 1.24^{* *}$ & $19.83 \pm 0.98^{* *}$ & $19.80 \pm 1.58^{* *}$ \\
\hline$\left[\mathrm{SIG}_{\mathrm{alb}}\right]$ & Fasting & $-7.53 \pm 1.23$ & $-6.97 \pm 0.76$ & $-7.12 \pm 1.25$ & $-6.87 \pm 1.01$ & $-5.89 \pm 3.91$ & $-6.47 \pm 0.99$ & $-6.44 \pm 0.54$ & $-7.15 \pm 0.74$ & $-6.43 \pm 1.41$ \\
\hline \multirow[t]{3}{*}{$(\mathrm{mmol} / \mathrm{L})$} & NP & $-5.20 \pm 1.10$ & $-4.97 \pm 1.66$ & $-4.75 \pm 2.03$ & $-4.28 \pm 1.66$ & $-4.16 \pm 1.24$ & $-3.85 \pm 1.10$ & $-4.36 \pm 1.67$ & $-4.40 \pm 1.25$ & $-4.39 \pm 1.83$ \\
\hline & Water-ORS & $-6.92 \pm 4.57$ & $-3.18 \pm 1.95^{* *}$ & $-3.54 \pm 0.77^{* *}$ & $-3.64 \pm 1.28^{*}$ & $-3.67 \pm 1.03^{*}$ & $-3.09 \pm 1.72^{* *}$ & $-3.80 \pm 1.62^{*}$ & $-4.02 \pm 1.61$ & $-3.58 \pm 1.39^{* *}$ \\
\hline & MR-ORS & $-4.47 \pm 2.75$ & $-4.60 \pm 2.76$ & $-3.94 \pm 2.89$ & $-4.56 \pm 2.57$ & $-4.78 \pm 2.28$ & $-5.11 \pm 2.48$ & $-4.75 \pm 2.06$ & $-4.95 \pm 2.76$ & $-5.47 \pm 2.06$ \\
\hline & Fasting & $-4.72 \pm 1.33$ & $-3.90 \pm 1.21$ & $-4.03 \pm 1.92$ & $-3.62 \pm 1.58$ & $-2.84 \pm 3.44$ & $-2.97 \pm 1.48$ & $-2.91 \pm 0.78$ & $-3.21 \pm 1.19$ & $-2.43 \pm 1.97$ \\
\hline \multirow{3}{*}{$(\mathrm{mmol} / \mathrm{L})$} & & $-3.49 \pm 0.47$ & $-3.19 \pm 0.89$ & $-2.85 \pm 1.64$ & $-2.32 \pm 1.33$ & $-2.19 \pm 1.50$ & $-1.74 \pm 1.36$ & $-2.01 \pm 1.01$ & $-1.81 \pm 1.02$ & $-1.52 \pm 1.31$ \\
\hline & Water-ORS & $-5.43 \pm 4.78$ & $-1.45 \pm 2.31^{* *}$ & $-1.70 \pm 1.38^{* *}$ & $-1.74 \pm 1.80^{* *}$ & $-1.67 \pm 1.64^{* *}$ & $-1.01 \pm 2.40^{* *}$ & $-1.64 \pm 2.15^{* *}$ & $-1.67 \pm 2.22^{* *}$ & $-1.03 \pm 1.43^{* *}$ \\
\hline & MR-ORS & $-3.03 \pm 3.05$ & $-2.92 \pm 3.10$ & $-2.21 \pm 3.26$ & $-2.72 \pm 2.93$ & $-2.79 \pm 2.57$ & $-3.02 \pm 2.91$ & $-2.59 \pm 2.59$ & $-2.66 \pm 3.36$ & $-2.99 \pm 2.57$ \\
\hline
\end{tabular}

${ }^{1}$ Strong ion difference $\left[\mathrm{SID}_{3}\right]=\left[\mathrm{Na}^{+}\right]+\left[\mathrm{K}^{+}\right]-\left[\mathrm{Cl}^{-}\right]$; acid total calculated from albumin $\left[\mathrm{A}_{\text {tot-alb }}\right]=0.622 \times[$ albumin $]$; acid total calculated from total protein $\left[\mathrm{A}_{\text {tot-TP }}\right]=0.343 \times$ 
experimental period of $240 \mathrm{~min}$ (Table 4). Independent of the feeding regimen, plasma-[L-lactate] decreased to its original values at an average time of $15 \mathrm{~min}$, whereas [D-lactate] values remained clearly elevated for longer than $240 \mathrm{~min}$. The [D-lactate] values decreased significantly $60 \mathrm{~min}$ after receiving MR, water- and MR-ORS. During the fasting period this decrease could be detected after 120 min. Elimination half time was not obtained within the observation period (Figures 3 and 4$)$. The $\left[\mathrm{SIG}_{\mathrm{alb} / \mathrm{TP}}\right]$ values increased significantly in all groups without any remarkable differences in between (Tables 3 and 4). The residuals of the regression analysis showed that a quadratic equation fit the data better than a linear function $\left([\text { lactate }]^{2}=\beta[\right.$ SIG $]+$ calf) (Figure 5) and that the slope was not influenced by the calf; this can be seen by the small standard error of the slope (Tables 5 and 6 ).

\section{Dietary Effects on Plasma Calcium}

A faster reduction of plasma calcium concentration could be detected among the feeding groups. In calves with lactic acidosis, values changed significantly after $45 \mathrm{~min}$ in the water-ORS group and feeding of MR and MR-ORS led to a significant decline after $90 \mathrm{~min}$, whereas the plasma calcium concentration in the fasting group changed after $240 \mathrm{~min}$ (Table 4). Differences in calves with $\mathrm{HCl}$ infusion were less obvious. Values of the fasting and MR-ORS groups changed significantly after $120 \mathrm{~min}$ and after $90 \mathrm{~min}$ in the MR-group. The decline was decelerated after water-ORS feeding (Table $3)$.

\section{Dietary Effects on Plasma Osmolality}

Plasma osmolality was not influenced significantly by any feeding regimen in the $\mathrm{HCl}$ or in the DL-lactic acidosis group (data not shown).

\section{DISCUSSION}

Effects of the feeding regimen on acid-base status after $\mathrm{HCl}$ or DL-lactate infusions were rare in the current study. In most cases, change of acid-base status was similar between the feeding regimens and fasting conditions; in a few cases, an earlier decrease or increase of parameters $\left(\left[\mathrm{Ca}^{2+}\right]\right.$, [D-lactate], $\left.\left[\mathrm{SID}_{3 / 4}\right]\right)$ after feeding could be detected. These effects might be due to fluid or electrolyte administration in general, but not to a specific feeding regimen, as no consistent effect of regimen was found. Due to infusion, and in contrast to diarrheic calves which are dehydrated, plasma volume was expanded, which is likely the reason why only minimal effects of oral rehydration therapy could be determined. Some positive effects on plasma- $\left[\mathrm{Ca}^{2+}\right]$, [D-lactate], and $\left[\mathrm{SID}_{3 / 4}\right]$ were detected, which might be relevant for the therapy of D-lactic or hyperchloremic acidosis in diarrheic calves. However, according to our results, we cannot recommend whether ORS should be prepared in MR, milk, or water to reduce metabolic acidosis in diarrheic calves more effectively. In general, it can be stated that the protocols to induce D-lactate and hyperchloremic acidosis are not suitable to study the effects of ORS on acid-base status as diarrheic calves suffer from acidosis and dehydration. A protocol to experimentally induce metabolic acidosis and dehydration simultaneously is needed to study the effects of oral and intravenous fluid administration on acid-base status. One possible way to induce hyperchloremic acidosis and dehydration is by intravenous application of $5 \mathrm{M} \mathrm{NH}_{4} \mathrm{Cl}$ (Iwabuchi et al., 2003), but this protocol is also not applicable to study effects of ORS. In contrast to diarrheic calves, in calves receiving $\mathrm{NH}_{4} \mathrm{Cl}$ plasma osmolality increases ( $>300 \mathrm{mmol} / \mathrm{L})$ and, without treatment, plasma volume and acid-base parameters return to baseline within 120 or $180 \mathrm{~min}$, respectively. Therefore, this experimental induction of acidosis and dehydration is only suitable to study the effects of intravenous administration as this treatment is immediately effective. D-Lactatemia without hyperhydration can also be triggered by infusion of $100 \mathrm{~mL}$ of sodium D-lactate (25 g, $223.1 \mathrm{mmol}$; Lorenz et al., 2005). However, this protocol does not provide metabolic acidosis besides raising plasma osmolality. Walker et al. (1998) published a protocol for the induction of dehydration, but the method only induced mild metabolic acidosis. This protocol was previously used to compare 2 ORS for their effectiveness to correct dehydration (Constable et al., 2001). Recently, Leal et al. (2012) also used this protocol without the usage of furosemide to study the effects of hypertonic saline solution on fluid and acidbase status. In that study, lower values of venous $\mathrm{pH}$ were obtained than in the original publication. However, failure to induce severe metabolic acidosis with $\mathrm{pH}<7.2$, base excess $<-3$, and SIG $<-3$ was also included. In another study (Nakagawa et al., 2009), metabolic acidosis was induced via oral administration of stearic acid. Maybe the combination of the protocol of Walker et al. (1998) or Leal et al. (2012) with oral administration of D-lactate or $\mathrm{HCl}$, respectively, could be used to copy the metabolic alterations of diarrheic calves.

Normally, severe acidosis in diarrheic calves leads to a decline in $\mathrm{pCO}_{2}$, as $\mathrm{CO}_{2}$ disposal via respiration is activated as a compensatory mechanism to reduce metabolic acidosis (Berchtold et al., 2000). However, no decrease in $\mathrm{pCO}_{2}$ after $\mathrm{HCl}$ infusion was observed during the experimental period, although $\mathrm{pH}$ was con- 
Table 4. Change of plasma parameters (mean $\pm \mathrm{SD}$ ) during a 4-h fasting period and after feeding milk replacer (MR), water-based oral rehydration solution (Water-ORS), and MR-based ORS (MR-ORS) in calves with experimentally induced DL-lactic acidosis $(\mathrm{n}=4)$

\begin{tabular}{|c|c|c|c|c|c|c|c|c|c|c|}
\hline Parameter $^{1}$ & Group & $-5 \min$ & $+15 \min$ & $+30 \mathrm{~min}$ & $+45 \mathrm{~min}$ & $+60 \mathrm{~min}$ & $+90 \mathrm{~min}$ & $+120 \min$ & $+180 \min$ & $+240 \min$ \\
\hline \multirow[t]{4}{*}{$\mathrm{pH}$} & Fasting & $7.11 \pm 0.13$ & $7.23 \pm 0.05^{*}$ & $7.25 \pm 0.05^{* *}$ & $7.26 \pm 0.05^{* *}$ & $7.25 \pm 0.05^{* *}$ & $7.27 \pm 0.03^{* *}$ & $7.26 \pm 0.06^{* *}$ & $7.29 \pm 0.05^{* *}$ & $7.28 \pm 0.07^{* *}$ \\
\hline & $\mathrm{MR}$ & $7.17 \pm 0.06$ & $7.22 \pm 0.05$ & $7.27 \pm 0.05$ & $7.26 \pm 0.06$ & $7.29 \pm 0.04^{*}$ & $7.29 \pm 0.07^{*}$ & $7.31 \pm 0.05^{* *}$ & $7.32 \pm 0.06^{* *}$ & $7.34 \pm 0.02^{* *}$ \\
\hline & Water-ORS & $7.05 \pm 0.14$ & $7.19 \pm 0.06^{* *}$ & $7.21 \pm 0.05^{* *}$ & $7.22 \pm 0.05^{* *}$ & $7.24 \pm 0.04^{* *}$ & $7.25 \pm 0.04^{* *}$ & $7.28 \pm 0.03^{* *}$ & $7.30 \pm 0.05^{* *}$ & $7.32 \pm 0.03^{* *}$ \\
\hline & MR-ORS & $7.09 \pm 0.13$ & $7.23 \pm 0.10^{* *}$ & $7.25 \pm 0.06^{* *}$ & $7.24 \pm 0.08^{* *}$ & $7.26 \pm 0.05^{* *}$ & $7.27 \pm 0.07^{* *}$ & $7.28 \pm 0.06^{* *}$ & $7.31 \pm 0.08^{* *}$ & $7.34 \pm 0.04^{* *}$ \\
\hline \multirow{4}{*}{$\begin{array}{l}{\left[\mathrm{Ca}^{2+}\right]} \\
(\mathrm{mmol} / \mathrm{L})\end{array}$} & Fasting & $1.43 \pm 0.03$ & $1.45 \pm 0.04$ & $1.44 \pm 0.03$ & $1.44 \pm 0.03$ & $1.41 \pm 0.03$ & $1.41 \pm 0.04$ & $1.39 \pm 0.03$ & $1.37 \pm 0.05$ & $1.35 \pm 0.08^{*}$ \\
\hline & MR & $1.46 \pm 0.05$ & $1.43 \pm 0.03$ & $1.43 \pm 0.02$ & $1.42 \pm 0.02$ & $1.40 \pm 0.03$ & $1.38 \pm 0.05^{* *}$ & $1.38 \pm 0.04^{*}$ & $1.38 \pm 0.03^{* *}$ & $1.36 \pm 0.03^{* *}$ \\
\hline & Water-ORS & $1.45 \pm 0.06$ & $1.40 \pm 0.05$ & $1.39 \pm 0.06$ & $1.37 \pm 0.05^{* *}$ & $1.37 \pm 0.05^{* *}$ & $1.36 \pm 0.05^{* *}$ & $1.35 \pm 0.04^{* *}$ & $1.33 \pm 0.04^{* *}$ & $1.33 \pm 0.03^{* *}$ \\
\hline & MR-ORS & $1.38 \pm 0.05$ & $1.38 \pm 0.08$ & $1.34 \pm 0.05$ & $1.32 \pm 0.05$ & $1.33 \pm 0.08$ & $1.30 \pm 0.04^{* *}$ & $1.31 \pm 0.07^{*}$ & $1.29 \pm 0.07^{* *}$ & $1.31 \pm 0.07^{*}$ \\
\hline \multirow{4}{*}{$\begin{array}{l}{\left[\mathrm{SID}_{4}\right]} \\
(\mathrm{mmol} / \mathrm{L})\end{array}$} & Fasting & $33.49 \pm 5.25$ & $33.86 \pm 4.54$ & $34.14 \pm 4.88$ & $34.62 \pm 4.37$ & $33.99 \pm 4.20$ & $34.84 \pm 4.45$ & $35.08 \pm 4.38$ & $35.48 \pm 4.60$ & $35.40 \pm 4.85$ \\
\hline & MR & $32.98 \pm 2.11$ & $34.42 \pm 1.42$ & $34.96 \pm 1.89$ & $35.44 \pm 1.52$ & $36.12 \pm 3.26^{*}$ & $36.66 \pm 2.89^{* *}$ & $37.03 \pm 1.59^{* *}$ & $36.84 \pm 2.47^{* *}$ & $37.31 \pm 1.65^{* *}$ \\
\hline & Water-ORS & $29.97 \pm 4.18$ & $31.66 \pm 3.47$ & $32.25 \pm 4.48$ & $31.57 \pm 4.40$ & $32.92 \pm 4.00$ & $34.16 \pm 4.74^{* *}$ & $34.23 \pm 3.72^{* *}$ & $35.68 \pm 3.44^{* *}$ & $36.21 \pm 3.47^{* *}$ \\
\hline & MR-ORS & $32.35 \pm 4.31$ & $33.53 \pm 3.71$ & $34.83 \pm 3.64$ & $34.60 \pm 3.49$ & $35.07 \pm 3.86$ & $36.45 \pm 3.79^{* *}$ & $37.27 \pm 3.47^{* *}$ & $38.16 \pm 3.31^{* *}$ & $38.54 \pm 3.85^{* *}$ \\
\hline \multirow{4}{*}{$\begin{array}{l}{\left[\mathrm{A}_{\text {tot-alb }}\right]} \\
(\mathrm{mmol} / \mathrm{L})\end{array}$} & Fasting & $14.90 \pm 1.23$ & $15.50 \pm 1.18$ & $15.47 \pm 1.20$ & $15.47 \pm 1.54$ & $15.27 \pm 1.16$ & $15.49 \pm 1.25$ & $15.38 \pm 1.42$ & $15.67 \pm 1.11$ & $15.38 \pm 1.46$ \\
\hline & MR & $15.18 \pm 0.40$ & $16.33 \pm 0.63$ & $15.99 \pm 0.94$ & $16.27 \pm 1.11$ & $16.17 \pm 1.16$ & $16.23 \pm 0.74$ & $15.94 \pm 1.04$ & $15.92 \pm 0.38$ & $15.55 \pm 0.73$ \\
\hline & Water-ORS & $13.90 \pm 0.67$ & $15.75 \pm 1.40^{*}$ & $15.33 \pm 1.65$ & $14.90 \pm 1.93$ & $14.93 \pm 1.51$ & $14.93 \pm 1.69$ & $14.88 \pm 1.58$ & $15.05 \pm 1.52$ & $14.76 \pm 1.71$ \\
\hline & MR-ORS & $15.21 \pm 0.69$ & $16.55 \pm 1.55$ & $16.47 \pm 1.74$ & $16.41 \pm 1.75$ & $16.42 \pm 1.79$ & $16.79 \pm 1.79$ & $16.42 \pm 1.79$ & $16.42 \pm 1.82$ & $16.31 \pm 1.28$ \\
\hline \multirow{4}{*}{$\begin{array}{l}{\left[\mathrm{A}_{\text {tot-TP }}\right]} \\
(\mathrm{mmol} / \mathrm{L})\end{array}$} & Fasting & $20.65 \pm 2.54$ & $21.78 \pm 2.40$ & $21.45 \pm 2.12$ & $21.45 \pm 1.56$ & $21.32 \pm 1.48$ & $21.87 \pm 2.29$ & $21.64 \pm 2.30$ & $22.04 \pm 1.86$ & $21.53 \pm 2.24$ \\
\hline & MR & $20.03 \pm 3.18$ & $20.99 \pm 3.49$ & $20.59 \pm 3.28$ & $20.55 \pm 2.82$ & $20.27 \pm 2.95$ & $21.10 \pm 3.23$ & $20.92 \pm 3.19$ & $20.98 \pm 3.13$ & $20.34 \pm 3.38$ \\
\hline & Water-ORS & $20.05 \pm 3.17$ & $20.61 \pm 3.62^{* *}$ & $20.22 \pm 3.39$ & $20.04 \pm 2.90$ & $19.93 \pm 2.98$ & $20.76 \pm 3.35$ & $20.66 \pm 3.28$ & $20.73 \pm 3.24^{*}$ & $20.01 \pm 3.47$ \\
\hline & MR-ORS & $18.45 \pm 1.62$ & $19.35 \pm 1.94$ & $19.19 \pm 1.94$ & $19.47 \pm 2.01$ & $19.47 \pm 2.30$ & $19.73 \pm 1.75$ & $19.59 \pm 1.66$ & $19.72 \pm 1.97$ & $18.74 \pm 1.55$ \\
\hline$\left[\mathrm{SIG}_{\mathrm{alb}}\right]$ & Fasting & $-21.59 \pm 2.78$ & $-17.44 \pm 2.12^{* *}$ & $-17.05 \pm 2.06^{* *}$ & $-16.45 \pm 2.05^{* *}$ & $-15.86 \pm 2.48^{* *}$ & $-15.60 \pm 2.33^{* *}$ & $-15.32 \pm 2.42^{* *}$ & $-14.50 \pm 2.18^{* *}$ & $-13.76 \pm 3.02^{* *}$ \\
\hline \multirow{3}{*}{$(\mathrm{mmol} / \mathrm{L})$} & $\mathrm{MR}$ & $-20.19 \pm 0.56$ & $-16.80 \pm 2.53$ & $-15.38 \pm 3.07^{* *}$ & $-14.93 \pm 3.49 * *$ & $-14.59 \pm 3.39^{* *}$ & $-13.92 \pm 3.02^{* *}$ & $-13.58 \pm 3.94^{* *}$ & $-12.01 \pm 4.34^{* *}$ & $-11.50 \pm 4.06^{* *}$ \\
\hline & Water-ORS & $-22.15 \pm 1.50$ & $-17.59 \pm 0.59^{* *}$ & $-16.48 \pm 1.92^{* *}$ & $-15.21 \pm 1.71^{* *}$ & $-15.77 \pm 1.47^{* *}$ & $-14.37 \pm 2.14^{* *}$ & $-13.67 \pm 2.03^{* *}$ & $-12.34 \pm 1.72^{* *}$ & $-12.28 \pm 2.03^{* *}$ \\
\hline & MR-ORS & $-22.08 \pm 1.68$ & $-17.57 \pm 0.98^{* *}$ & $-17.37 \pm 0.67^{* *}$ & $-17.18 \pm 1.35^{* *}$ & $-16.24 \pm 1.46^{* *}$ & $-16.15 \pm 1.12^{* *}$ & $-15.38 \pm 1.23^{* *}$ & $-14.50 \pm 0.63^{* *}$ & $-12.79 \pm 1.27^{* *}$ \\
\hline \multirow{4}{*}{$\begin{array}{l}{\left[\mathrm{SIG}_{\mathrm{TP}}\right]} \\
(\mathrm{mmol} / \mathrm{L})\end{array}$} & Fasting & $-18.55 \pm 4.00$ & $-13.73 \pm 3.39^{* *}$ & $-13.46 \pm 2.95^{* *}$ & $-12.82 \pm 3.16^{* *}$ & $-12.23 \pm 3.28^{* *}$ & $-11.71 \pm 3.49^{* *}$ & $-11.51 \pm 3.74^{* *}$ & $-10.53 \pm 3.13^{* *}$ & $-9.93 \pm 4.00^{* *}$ \\
\hline & MR & $-19.01 \pm 0.23$ & $-15.43 \pm 2.99$ & $-13.86 \pm 3.27^{* *}$ & $-13.27 \pm 3.86^{* *}$ & $-12.80 \pm 4.05^{* *}$ & $-11.92 \pm 3.53^{* *}$ & $-11.59 \pm 4.32^{* *}$ & $-9.92 \pm 5.02^{* *}$ & $-9.51 \pm 4.46^{* *}$ \\
\hline & Water-ORS & $-20.96 \pm 2.25$ & $-15.76 \pm 1.57^{* *}$ & $-14.78 \pm 2.23^{* *}$ & $-13.48 \pm 2.24^{* *}$ & $-13.94 \pm 2.12^{* *}$ & $-12.43 \pm 2.51^{* *}$ & $-11.47 \pm 2.88^{* *}$ & $-10.08 \pm 2.64^{* *}$ & $-10.02 \pm 2.85^{* *}$ \\
\hline & MR-ORS & $-19.37 \pm 2.79$ & $-14.41 \pm 1.67^{* *}$ & $-14.07 \pm 1.49^{* *}$ & $-13.90 \pm 1.98^{* *}$ & $-12.87 \pm 1.78^{* *}$ & $-12.69 \pm 1.73^{* *}$ & $-11.87 \pm 2.16^{* *}$ & $-10.85 \pm 2.06^{* *}$ & $-9.24 \pm 2.35^{* *}$ \\
\hline
\end{tabular}

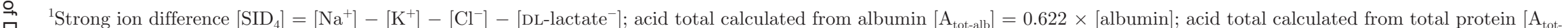
$\left.\stackrel{\text { N. }}{\Sigma} \mathrm{TP}_{\mathrm{T}}\right]=0.343 \times[\mathrm{TP}]$; strong ion gap calculated from albumin $\left[\mathrm{SIG}_{\mathrm{alb}}\right]=[$ albumin $] \times\left\{0.622 /\left[1+10^{(7.08-\mathrm{pH})}\right]\right\}-$ anion gap; strong ion gap calculated from total protein $[\mathrm{SIG}$ TP $]=$ œ $[\mathrm{TP}] \times\left\{0.343 /\left[1+10^{(7.08-\mathrm{pH})}\right]\right\}-$ anion gap.

$\stackrel{\curvearrowright}{\Phi}$. $\quad * P<0.05, * * P<0.01$ compared with values immediately after infusion and before feeding $(t=-5 \mathrm{~min})$. 
D-lactate

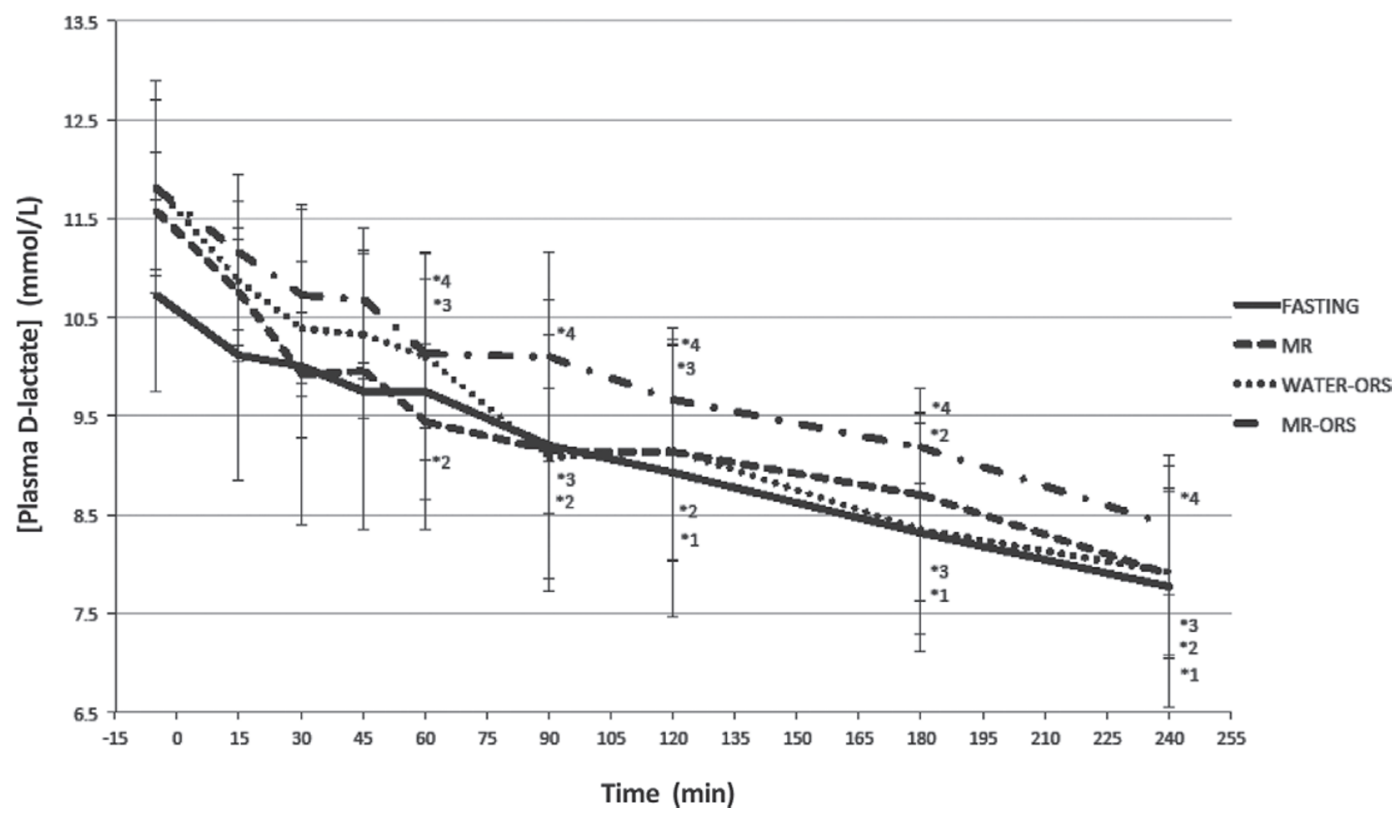

Figure 3. Change in plasma [D-lactate] during a 4-h fasting period and after feeding milk replacer (MR) or water- or MR-based oral rehydration solutions (water-ORS or MR-ORS) with experimentally induced DL-lactate acidosis. Asterisks $(*)$ indicate statistically significant differences compared with the time $=-5$ min value $(P<0.05)$. Numbered asterisks $(*)$ indicate individual feeding regimens: ${ }^{*} 1=$ fasting; ${ }^{*} 2$ $=\mathrm{MR} ; *^{*}=$ water-ORS; $* 4=$ MR-ORS.

\section{L-lactate}

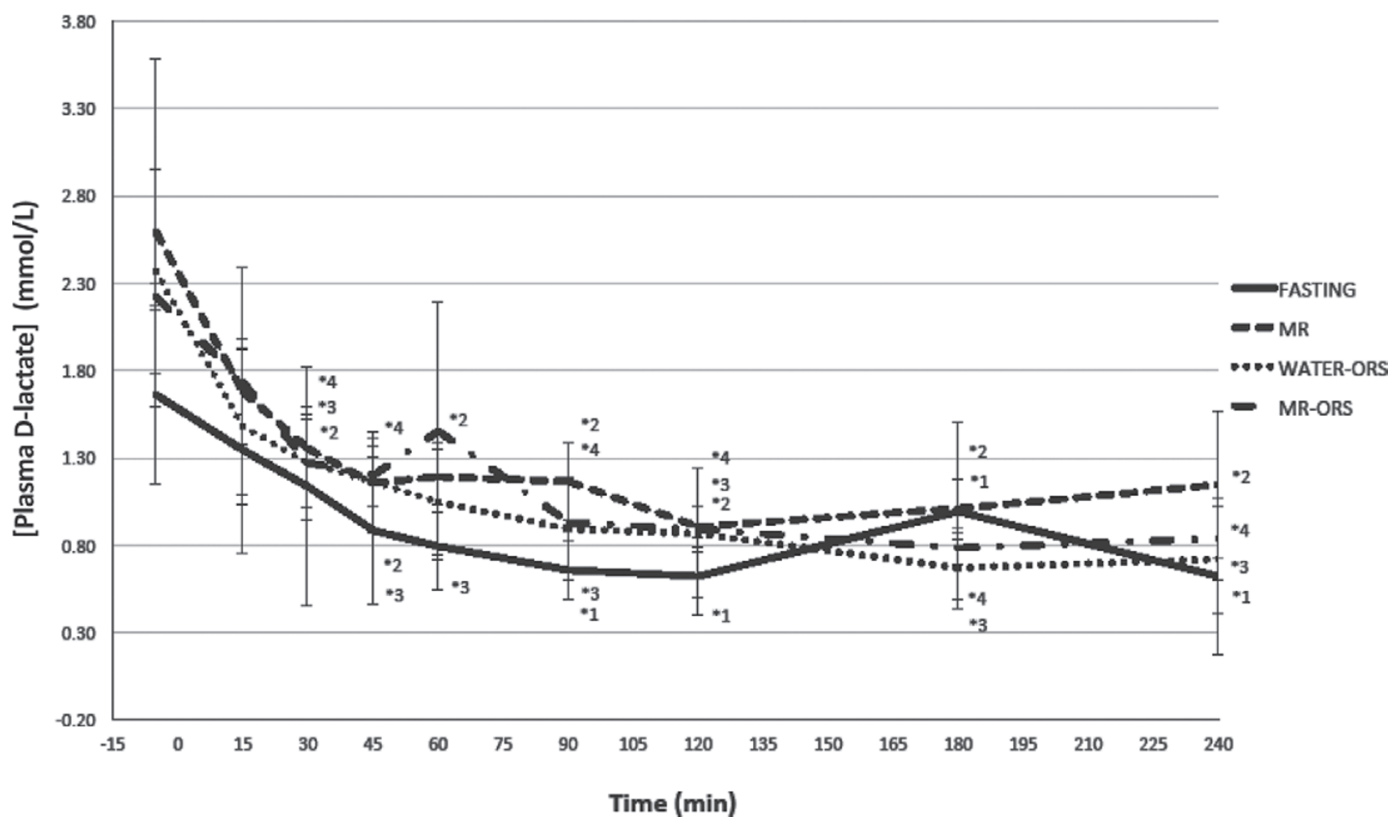

Figure 4. Change in plasma-[L-lactate] during a 4-h fasting period and after feeding milk replacer (MR) or water- or MR-based oral rehydration solutions (water-ORS or MR-ORS) in calves with experimentally induced DL-lactate acidosis. Asterisks $(*)$ indicate statistically significant differences compared with the time $=-5$ min value $(P<0.05)$. Numbered asterisks $(*)$ indicate individual feeding regimens: $* 1=$ fasting; ${ }^{*} 2$ $=\mathrm{MR} ;{ }^{*} 3=$ water-ORS; $* 4=$ MR-ORS. 
Table 5. Linear regression analysis between strong ion gap calculated from albumin $\left[\mathrm{SIG}_{\mathrm{alb}}\right]$ and [DL-lactate]

\begin{tabular}{lcl}
\hline Item $^{1}$ & Estimate & SE \\
\hline Intercept & -39.7 & 6.87 \\
Slope & -9.82 & 0.32 \\
Calf 2 & 5.75 & 5.61 \\
Calf 3 & 20.4 & 5.64 \\
Calf 4 & 17.0 & 6.13 \\
Calf 5 & 17.6 & 5.61 \\
Calf 6 & -17.0 & 5.63 \\
\hline
\end{tabular}

${ }^{1}$ The different calves considered have been included as dummy variables. The intercept corresponds to choosing calf 1 (treatment contrasts).

stantly low. Interestingly, after DL-lactic acid infusion, the average $\mathrm{pCO}_{2}$ decreased gradually in all groups, though this effect was not significant. The increase of lactate is one mechanism discussed to promote breathing during muscular exercise (Whipp and Ward, 1998). According to our data, lactate accumulation seems to reinforce respiration more powerful than the decline of $\mathrm{pH}$.

The calculated $\left[A_{\text {tot-alb }}\right]$ values of the calves used in the present study $(\sim 16 \mathrm{mmol} / \mathrm{L}$ before infusions) were lower than the reference values $(\sim 20 \mathrm{mmol} / \mathrm{L})$ suggested by Constable et al. (2005). The calculation of $\left[\mathrm{A}_{\text {tot }}\right]$ according to Constable et al. (2005) was applied by using the reference values of 9 healthy calves aged 4 to $55 \mathrm{~d}$ that presented an [albumin] of $30.9 \mathrm{~g} / \mathrm{L}$. However, calves $<14 \mathrm{~d}$ often have albumin concentrations below
Table 6. Linear regression analysis between strong ion gap calculated from total protein $\left[\mathrm{SIG}_{\mathrm{TP}}\right]$ and [DL-lactate]

\begin{tabular}{lcl}
\hline Item $^{1}$ & Estimate & SE \\
\hline Intercept & -28.4 & 5.99 \\
Slope & -9.65 & 0.29 \\
Calf 2 & 16.9 & 5.18 \\
Calf 3 & 43.0 & 5.32 \\
Calf 4 & 25.6 & 5.65 \\
Calf 5 & 30.2 & 5.20 \\
Calf 6 & 22.2 & 5.44 \\
\hline
\end{tabular}

${ }^{1}$ The different calves considered have been included as dummy variables. The intercept corresponds to choosing calf 1 (treatment contrasts).

30.9 g/L (Knowles et al., 2000; Mohri et al., 2007; Bachmann et al., 2009a). Due to low plasma-[albumin] before infusions, $\left[\mathrm{SIG}_{\mathrm{alb}}\right]$ exceeded the proposed reference range $(-3$ to $+3 \mathrm{mmol} / \mathrm{L})$. As [total protein] of calves was not diminished, $\left[\mathrm{A}_{\text {tot-TP }}\right]$ and $\left[\mathrm{SIG}_{\mathrm{TP}}\right]$ were within the suggested reference range. Nevertheless, the decrease of $\left[\mathrm{SIG}_{\mathrm{alb}}\right]$ and $\left[\mathrm{SIG}_{\mathrm{TP}}\right]$ after DL-lactic acid infusion reflected the increase of [DL-lactate] in plasma; however, the association of [lactate] and [SIG] was not linear, but quadratic $\left([\text { lactate }]^{2}=\beta[\mathrm{SIG}]+\right.$ calf $)$, which means the proportion of [lactate] and [SIG] was not 1:1. Therefore, more research of reference values for $\left[\mathrm{A}_{\mathrm{tot}}\right]$ and $[\mathrm{SIG}]$ in young calves is needed in the regard that [SIG] can be used to detect unidentified strong anions (predominantly D-lactate) in plasma of diarrheic calves.

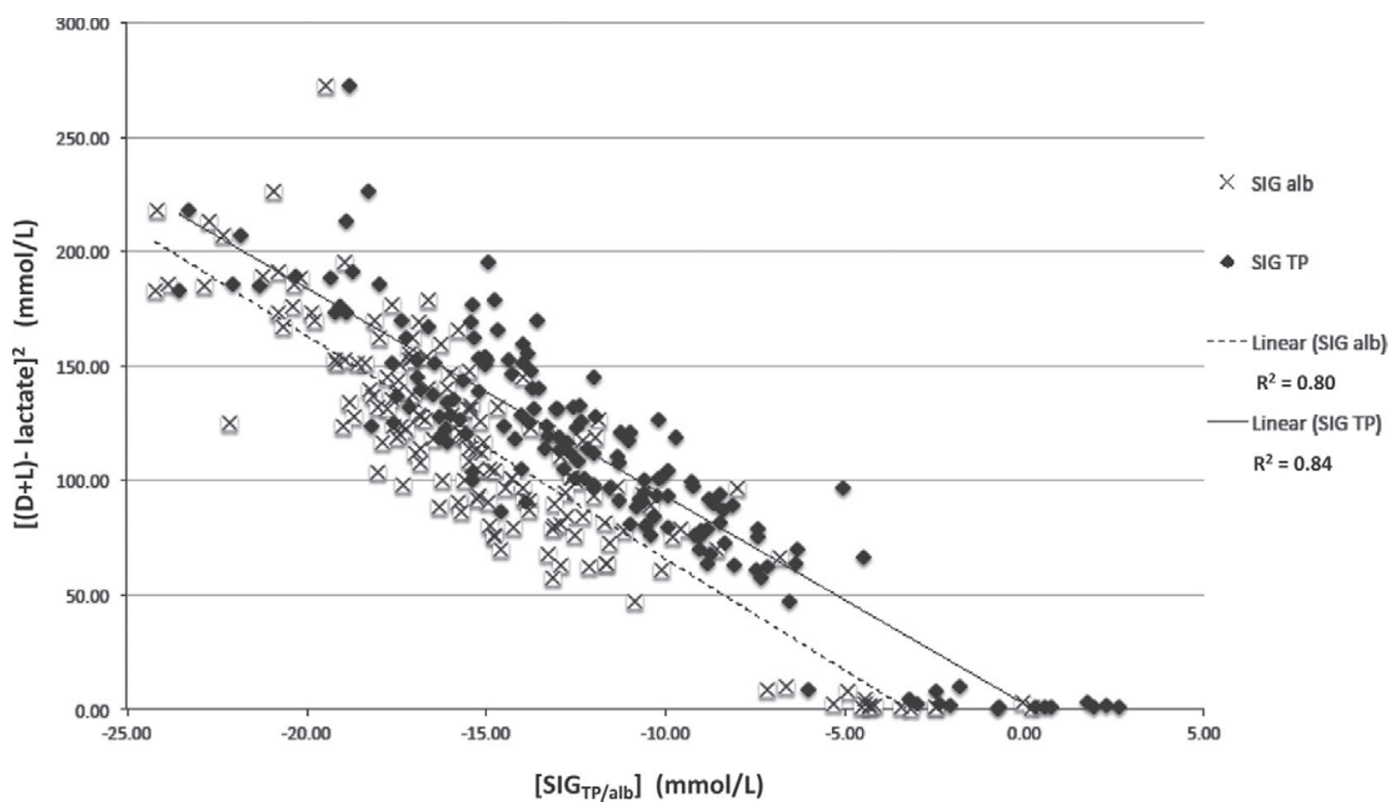

Figure 5. Scatter plot of the relationship between [DL-lactate] and strong ion gap calculated from albumin: $\left[\mathrm{SIG}_{\mathrm{alb}}\right]=[\mathrm{albumin}] \times\{0.622 /[1$ $\left.\left.+10^{(7.08-\mathrm{pH})}\right]\right\}$ - anion gap, or strong ion gap calculated from total protein: $\left[\mathrm{SIG}_{\mathrm{TP}}\right]=[$ total protein $] \times\left\{0.343 /\left[1+10^{(7.08-\mathrm{pH})}\right]\right\}-$ anion gap, in plasma samples after induction of lactic acidosis. 
D-Lactate concentrations generated by the DL-lactic infusion protocol were in the estimated reference range $(8.8 \pm 5.0 \mathrm{mmol} / \mathrm{L})$ of diarrheic calves (Lorenz, 2004). The plasma half-life of D-lactate in the present study was longer $(>180 \mathrm{~min})$ than in the study of Lorenz et al. (2005), which might be due to metabolic acidosis. In vitro, the activity of the D-lactate eliminating enzyme (D-2-hydroxy acid dehydrogenase) is diminished by a low $\mathrm{pH}$ (Tubbs, 1965). For this reason, calves suffering from diarrhea might reveal hyper-D-lactatemia (Lorenz et al., 2005).

With the present study we cannot confirm that the induction of hyperchloremic acidosis, according to Gentile et al. (2008), has no effects on calf's behavior, as 2 calves' suckle reflex suspended after $\mathrm{HCl}-$ infusion. This result is consistent with the research of Abeysekara et al. (2007), in which suckle reflex was similarly depressed by DL-lactic acid and HCl-infusion. Furthermore, the fact that L-lactate level was reduced to baseline values much faster than D-lactate, whereas symptoms of impaired nervous system sustained, proves that D-lactate alone is responsible for disturbance of central nervous function, as mentioned by Lorenz et al. (2005) and Abeysekara et al. (2007). In all clinical signs seen in the present study it should be emphasized that hyperchloremic and D-lactate acidosis can provoke clinical abnormalities. Correction of acid-base status is always needed to prevent malfunction of suckle reflex and avoid usage of intravenous fluid administration.

As noted by Abeysekara et al. (2007) and Lorenz et al. (2005), D-lactate impairs central nervous system function; however, their publications offered no evidence that the infused calves developed thrombophlebitis. Thrombophlebitis after catherization and infusion is most likely due to chemical or mechanical irritation of the endothelium (Maki and Ringer, 1991). However, in our study, the prolonged duration of catheters or the low $\mathrm{pH}$ of the DL-lactic acid infusion can be precluded as the reason for the occurrence of thrombophlebitis. The conditions (catheter, duration of catheterization, infusion volumes) were nearly the same in both groups, and the $\mathrm{pH}$ of the $\mathrm{HCl}$ infusion solution was lower $(\mathrm{pH}$ $=1.2)$ than in the lactic acid infusate $(\mathrm{pH}=2.32)$. In the $\mathrm{HCl}$ group we did not notice thrombophlebitis in any calf. Recently, the effects of D-lactate on rats' brain, heart, and liver mitochondria were studied (Ling et al., 2012). In that study, D-lactate was a poor energy substrate in brain and heart mitochondria and inhibited L-lactate and pyruvate usage in those tissues. Perhaps this effect also occurs in endothelia cells and might be the reason for the development of massive thrombophlebitis and edema after repeated DL-lactic acid infusions. In another recently published study, the effects of methylglyoxal on endothelium were examined and methylglyoxal was found to promote endothelial dysfunction (Sena et al., 2012). Methylglyoxal is the precursor of endogenous produced D-lactate (Ewaschuk et al., 2005); no study exists that elucidates the interaction between D-lactate and the endothelium. It was hypothesized that high levels of D-lactate could provoke laminitis. However, one study showed that bull calves were fed a readily fermentable diet to induce laminitis via ruminal DL-lactic acid production. In that study, D-lactate increased but laminitis was not detected (Momcilovic et al., 2000). According to the massive vascular reaction after repetitive DL-lactic acid infusion in the present investigation, more research about the effects of D-lactate on the endothelium is required. Enduring high D-lactate levels in blood might play an important role in the pathogenesis of laminitis in cattle and horses.

Limitations of our study include study size - only 12 animals were examined - and that all calves were male, of Holstein-Friesian breed, and originated from the same farm. These factors might have influenced the results and should, therefore, be confirmed in future experiments in calves of other breeds, sex, and origin.

\section{CONCLUSIONS}

The induction of DL-lactate and hyperchloremic acidosis via infusion is not suitable to study dietary effects. A protocol to induce acidosis and dehydration simultaneously is needed to replicate metabolic conditions of calves suffering from diarrhea. High D-lactate concentrations can be found in humans and animals with gastrointestinal malfunction, diabetes, infection, ischemia, and traumatic shock. More investigations should be done considering the effects of D-lactate on the endothelium.

\section{ACKNOWLEDGMENTS}

This project was financially supported by Deutsche Forschungsgemeinschaft (Bonn, Germany). The authors thank Austin Bell (Barnfield Pet Hospital, Denver, CO) for linguistic revision of the manuscript, and Jana Tietke and Beatrice Ladanyi (Institute for Animal Nutrition, Nutrition Diseases and Dietetics, Universität Leipzig, Germany) for performing laboratory analyses.

\section{REFERENCES}

Abeysekara, S., J. M. Naylor, A. W. Wassef, U. Isak, and G. A. Zello. 2007. D-Lactic acid-induced neurotoxicity in a calf model. Am. J. Physiol. Endocrinol. Metab. 293:E558-565.

Azizzadeh, M., H. F. Shooroki, A. S. Kamalabadi, and M. A. Stevenson. 2012. Factors affecting calf mortality in Iranian Holstein dairy herds. Prev. Vet. Med. 104:335-340. 
Bachmann, L., J. Berchtold, C. Siegling-Vlitakis, A. Willing, E. Radtke, and H. Hartmann. 2009a. Stewart variables of the acidbase status in calves. Age related behaviour and influence of spontaneously occurring diarrhoea. Tierarztl. Prax. Ausg. G Grosstiere Nutztiere 37:365-374.

Bachmann, L., T. Homeier, S. Arlt, M. Brueckner, H. Rawel, C. Deiner, and H. Hartmann. 2009b. Influence of different oral rehydration solutions on abomasal conditions and the acid-base status of suckling calves. J. Dairy Sci. 92:1649-1659.

Bell, F. R., and S. A. Razig. 1973. Gastric emptying and secretion in the milk-fed calf. J. Physiol. 228:499-512.

Berchtold, J., H. Hartmann, and W. Hofmann. 2000. Bedeutung respiratorischer Kompensationsvorgänge bei Azidosen des Kalbes. Dtsch. Tierarztl. Wochenschr. 107:10-16.

Constable, P. D., W. Grunberg, and L. Carstensen. 2009. Comparative effects of two oral rehydration solutions on milk clotting, abomasal luminal $\mathrm{pH}$, and abomasal emptying rate in suckling calves. J. Dairy Sci. 92:296-312.

Constable, P. D., H. R. Stampfli, H. Navetat, J. Berchtold, and F. Schelcher. 2005. Use of a quantitative strong ion approach to determine the mechanism for acid-base abnormalities in sick calves with or without diarrhea. J. Vet. Intern. Med. 19:581-589.

Constable, P. D., E. Thomas, and B. Boisrame. 2001. Comparison of two oral electrolyte solutions for the treatment of dehydrated calves with experimentally induced diarrhoea. Vet. J. 162:129 141.

Ewaschuk, J. B., J. M. Naylor, and G. A. Zello. 2005. D-lactate in human and ruminant metabolism. J. Nutr. 135:1619-1625.

FASS. 2010. Guide for the Care and Use of Agricultural Animals in Research and Teaching. 3rd ed. Federation of Animal Science Societies, Champaign, IL.

Garthwaite, B. D., J. K. Drackley, G. C. McCoy, and E. H. Jaster. 1994. Whole milk and oral rehydration solution for calves with diarrhea of spontaneous origin. J. Dairy Sci. 77:835-843.

Gentile, A., I. Lorenz, S. Sconza, and W. Klee. 2008. Experimentally induced systemic hyperchloremic acidosis in calves. J. Vet. Intern. Med. 22:190-195.

Groutides, C. P., and A. R. Michell. 1990. Changes in plasma composition in calves surviving or dying from diarrhoea. Br. Vet. J. 146:205-210.

Grove-White, D. H., and A. R. Michell. 2001. Iatrogenic hypocalcaemia during parenteral fluid therapy of diarrhoeic calves. Vet. Rec. 149:203-207.

Hartmann, H., J. Berchtold, and W. Hofmann. 1997. Pathophysiological aspects of acidosis in diarrhoeic calves. Tierarztl. Umsch. 52:568-574.

Iwabuchi, S., K. Suzuki, I. Abe, and R. Asano. 2003. Comparison of the effects of isotonic and hypertonic sodium bicarbonate solutions on acidemic calves experimentally induced by ammonium chloride administration. J. Vet. Med. Sci. 65:1369-1371.

Knowles, T. G., J. E. Edwards, K. J. Bazeley, S. N. Brown, A. Butterworth, and P. D. Warriss. 2000. Changes in the blood biochemical and haematological profile of neonatal calves with age. Vet. Rec. 147:593-598.

Leal, M. L. R., S. S. Fialho, F. C. Cyrillo, H. G. Bertagnon, E. L. Ortolani, and F. J. Benesi. 2012. Intravenous hypertonic saline solution $(7.5 \%)$ and oral electrolytes to treat of calves with noninfectious diarrhea and metabolic acidosis. J. Vet. Intern. Med. 26:1042-1050.

Ling, B., F. Peng, J. Alcorn, K. Lohmann, B. Bandy, and G. A. Zello. 2012. D-Lactate altered mitochondrial energy production in rat brain and heart but not liver. Nutr. Metab. (Lond) 9:6. http:// dx.doi.org/10.1186/1743-7075-9-6.

Lorenz, I. 2004. Investigations on the influence of serum D-lactate levels on clinical signs in calves with metabolic acidosis. Vet. J. 168:323-327.

Lorenz, I. 2009. D-Lactic acidosis in calves. Vet. J. 179:197-203.

Lorenz, I., A. Gentile, and W. Klee. 2005. Investigations of D-lactate metabolism and the clinical signs of D-lactataemia in calves. Vet. Rec. 156:412-415.

Maki, D. G., and M. Ringer. 1991. Risk factors for infusion-related phlebitis with small peripheral venous catheters. Ann. Intern. Med. 114:845-854.

Mohri, M., D. Sharifi, and S. Eidi. 2007. Hematology and serum biochemistry of Holstein dairy calves: Age related changes and comparison with blood composition in adults. Res. Vet. Sci. 83:30-39.

Momcilovic, D., J. H. Herbein, W. D. Whittier, and C. E. Polan. 2000 Metabolic alterations associated with an attempt to induce laminitis in dairy calves. J. Dairy Sci. 83:518-525.

Nakagawa, M., K. Suzuki, F. Takahashi, K. Kamikatano, M. Koiwa, and K. Taguchi. 2009. Comparison of the alkalizing effects of bicarbonate precursors in calves with experimentally induced metabolic acidosis. J. Vet. Med. Sci. 71:807-809.

Radostits, O. M., C. S. Rhodes, M. E. Mitchell, T. P. Spotswood, and M. S. Wenkoff. 1975. A clinical evaluation of antimicrobial agents and temporary starvation in the treatment of acute undifferentiated diarrhea in newborn calves. Can. Vet. J. 16:219-227.

Sen, I., P. D. Constable, and T. S. Marshall. 2006. Effect of suckling isotonic or hypertonic solutions of sodium bicarbonate or glucose on abomasal emptying rate in calves. Am. J. Vet. Res. 67:13771384 .

Sena, C. M., P. Matafome, J. Crisostomo, L. Rodrigues, R. Fernandes, P. Pereira, and R. M. Seica. 2012. Methylglyoxal promotes oxidative stress and endothelial dysfunction. Pharmacol. Res. 65:497506 .

Staempfli, H. R., and P. D. Constable. 2003. Experimental determination of net protein charge and $\mathrm{A}($ tot $)$ and $\mathrm{K}(\mathrm{a})$ of nonvolatile buffers in human plasma. J. Appl. Physiol. 95:620-630.

Stewart, P. A. 1978. Independent and dependent variables of acid-base control. Respir. Physiol. 33:9-26.

Torsein, M., A. Lindberg, C. H. Sandgren, K. P. Waller, M. Tornquist, and C. Svensson. 2011. Risk factors for calf mortality in large Swedish dairy herds. Prev. Vet. Med. 99:136-147.

Tubbs, P. K. 1965. The metabolism of d-alpha hydroxy acids in animal tissues. Ann. N. Y. Acad. Sci. 119:920-926.

US Department of Agriculture. 2007. Dairy 2007 Part II: Changes in the US Dairy Cattle Industry, 1991-2007. Veterinary Services. National Animal Health Monitoring System. Animal and Plant Health Inspection Service, Fort Collins, CO.

Van Beaumont, W., J. Greenleaf, and L. Juhos. 1972. Disproportional changes in hematocrit, plasma-volume, and proteins during exercise and bed rest. J. Appl. Physiol. 33:55-61.

Walker, P. G., P. D. Constable, D. E. Morin, J. K. Drackley, J. H. Foreman, and J. C. Thurmon. 1998. A reliable, practical, and economical protocol for inducing diarrhea and severe dehydration in the neonatal calf. Can. J. Vet. Res. 62:205-213.

Whipp, B. J., and S. A. Ward. 1998. Determinants and control of breathing during muscular exercise. Br. J. Sports Med. 32:199211.

Wokes, F., and B. M. Still. 1942. The estimation of protein by the Biuret and Greenberg methods. Biochem. J. 36:797-806. 